\title{
The full-endoscopic uniportal technique for decompression of the anterior craniocervical junction using the retropharyngeal approach: an anatomical feasibility study in human cadavers and review of the literature
}

\author{
Sebastian Ruetten, MD, ${ }^{1}$ Patrick Hahn, MD, ${ }^{1}$ Semih Oezdemir, MD, ${ }^{1}$ Xenophon Baraliakos, MD, ${ }^{2}$ \\ Harry Merk, MD, ${ }^{3}$ Georgios Godolias, MD, ${ }^{4}$ and Martin Komp, MD ${ }^{5}$ \\ ${ }^{1}$ Center for Spine Surgery and Pain Therapy, Center for Orthopedics and Traumatology of the St. Elisabeth Group—Catholic \\ Hospital Rhein-Ruhr, St. Anna Hospital Herne/Marien Hospital Herne University Hospital of the Ruhr University of Bochum/ \\ Marien Hospital Witten, Herne; ${ }^{2}$ Center for Rheumatology, Rheumazentrum Ruhrgebiet, Ruhr University of Bochum, Herne; \\ ${ }^{3}$ Clinic for Orthopaedics and Orthopaedic Surgery, University Medicine Greifswald; ${ }^{4} \mathrm{Center}$ for Orthopedics and Traumatology \\ of the St. Elisabeth Group—Catholic Hospital Rhein-Ruhr, St. Anna Hospital Herne/Marien Hospital Herne University Hospital \\ of the Ruhr University Bochum/Marien Hospital Witten, Herne; and ${ }^{5}$ Center for Spine Surgery and Pain Therapy, Center for \\ Orthopedics and Traumatology of the St. Elisabeth Group—Catholic Hospital Rhein-Ruhr, St. Anna Hospital Herne, University of \\ Witten/Herdecke, Herne, Germany
}

OBJECTIVE Acute or progressive myelopathy may necessitate direct anterior decompression of the craniocervical junction and odontoidectomy. Different techniques with individual advantages and disadvantages can be used. In addition to the gold standard—-the transoral approach —-there is also increasing experience with the endoscopic transnasal technique. Other alternative methods are also being developed to reduce technical and perioperative problems. The aim of this anatomical study was to investigate the feasibility of the full-endoscopic uniportal technique with a retropharyngeal approach for decompression of the craniocervical junction, taking into consideration the specific advantages and disadvantages compared with conventional methods and the currently available data in the literature.

METHODS Five fresh adult cadavers were operated on. The endoscope used has a shaft cross-section of $6.9 \times 5.9$ $\mathrm{mm}$ and $\mathrm{a} 25^{\circ}$ viewing angle. It contains an eccentric intraendoscopic working channel with a diameter of $4.1 \mathrm{~mm}$. An anterior retropharyngeal approach was used. The anatomical structures of the anterior craniocervical junction were dissected and the bulbomedullary junction was decompressed.

RESULTS The planned steps of the operation were performed in all cadavers. The retropharyngeal approach allowed the target region to be accessed easily. The anatomical structures of the anterior craniocervical junction could be identified and dissected. The bulbomedullary junction could be adequately decompressed. No resections of the anterior arch of the atlas were necessary in the odontoidectomy.

CONCLUSIONS Using the full-endoscopic uniportal technique with an anterior retropharyngeal approach, the craniocervical region can be adequately reached, dissected, and decompressed. This is a minimally invasive technique with the known advantages of an endoscopic procedure under continuous irrigation. The retropharyngeal approach allows direct, sterile access. The instruments are available for clinical use and have been established for years in other operations of the entire spine.

https://thejns.org/doi/abs/10.3171/2018.4.SPINE171156

KEYWORDS cervicomedullary; craniocervical junction; full endoscopic; minimally invasive; odontoidectomy; retropharyngeal approach; cervical 
$\mathrm{A}$ NTERIOR compression of the brainstem can be caused by different pathologies of the craniocervical junction, such as instability with basilar impression, retrodental pannus due to rheumatic disease, congenital anomalies and syndromes, neoplastic processes, infections, and os odontoideum. ${ }^{2,5,33}$ In acute or progressive myelopathy due to irreducible bone compression, for example, soft-tissue pannus or abscess may necessitate direct anterior decompression and odontoidectomy. ${ }^{3,19,33}$ The operative approach to the anterior craniocervical junction may be complicated due to the deep location and surrounding neurovascular structures. Various alternative anterior, posterolateral, and lateral approaches have been described. 1,5,6,22,36

The transoral approach allows direct access and is the most common method..$^{5,719,24}$ However, operative-related problems and complications are known, such as velopharyngeal insufficiency, dysphonia, and dysphagia due to splitting the soft or hard palate to increase mobility, swelling of soft tissue with prolonged intubation or tracheostomy, risk of infection due to contamination of the operative field by bacterial flora of the oropharynx, or if the dura is opened, an increased risk of a CSF fistula due to insufficient soft-tissue coverage. ${ }^{2,5,32,34}$ As an alternative, the endoscopic transnasal approach was developed, which has technical advantages. ${ }^{1,3,11,12,15,20,23,37}$ Proceeding laterally or caudally, for example, has sometimes been described as problematic due to the hard palate, limitations of the nasal anatomy, or venous bleeding. ${ }^{1,20}$ It generally seems possible to reduce the problems of the transoral approach. ${ }^{4,12}$ Endoscope-assisted techniques that have advantages due to the retropharyngeal approach have also been described. ${ }^{6,36}$

Good outcomes and advantages have been described for full-endoscopic uniportal operations under continuous irrigation for herniated discs and spinal canal stenoses. ${ }^{16,26-28}$ Based on these descriptions of full-endoscopic operations on the spine, this anatomical study examines the feasibility of the full-endoscopic uniportal technique with an already described retropharyngeal approach for decompression of the craniocervical junction, taking into consideration the specific advantages and disadvantages compared with the known methods and currently available data in the literature.

\section{Methods}

Five fresh adult cadavers ( 2 female, 3 male) were operated on in this study. The research protocol for this study was reviewed and approved by the IRB of St. Elisabeth Group Hospital. The surgical retropharyngeal approach, the accessibility and dissection of the anatomical structures of the anterior craniocervical junction, and the technical possibilities and limitations of direct decompression of the bulbomedullary region were evaluated.

\section{Full-Endoscopic Instruments}

Full-endoscopic surgery is a surgical technique for the spinal canal and neighboring structures performed under continuous visual control and irrigation using an approach causing minimal trauma. It is not an endoscope-assisted procedure through a tubular retractor, but rather a uni- portal technique using endoscopes with intraendoscopic working channels. The endoscope used has an oval shaft cross-section measuring $6.9 \times 5.9 \mathrm{~mm}$, a working length of $165 \mathrm{~mm}$, and is introduced through a sheath. The viewing angle is $25^{\circ}$. For uniportal work, it has an eccentric intraendoscopic working channel with a diameter of 4.1 $\mathrm{mm}$, a light guide, a sheath for continuous irrigation, and a rod lens system. All surgical instruments are introduced through the working channel and are therefore used under continuous visual control. As known from conventional operations, various instruments and cutting tools of different diameters $(2-4 \mathrm{~mm})$ and angles are available, so this does not result in any disadvantages compared with other techniques. For coagulation, tissue ablation, and dissection, a bipolar articulating probe is used that applies the radiofrequency current of $4 \mathrm{MHz}$, which reduces the transmission of heat to adjacent tissue structures. ${ }^{13}$ The region is irrigated with an isotonic saline solution using an electric pump that controls the flow rate and limits irrigation pressure. The endoscopy system is used as an open system $^{16,27-29}$ so that due to the design, outflow is always greater than inflow. For the length of the working sheath of $130 \mathrm{~mm}$, the maximum pressure of the irrigation fluid is thus $9.6 \mathrm{~mm} \mathrm{Hg}$. On average, the CSF pressure in the high cervical region is $15.5 \mathrm{~mm} \mathrm{Hg},{ }^{14}$ thus minimizing the risk of compression or leakage of the irrigation fluid into the CSF system. All surgical and optical instruments were from RIWOspine GmbH.

\section{Surgical Approach and Dissection of the Craniocervical Junction}

The instrument setup complies with the usual standards for endoscopic operations. The procedure is performed with the patient supine and the head fixed. For right-handed operators, the operative approach is from the right and the required $\mathrm{C}$-arm system is positioned at the left. The approximate $8-\mathrm{mm}$ skin incision is made anterior to the sternocleidomastoid muscle, at about the level of the fourth or fifth vertebral body. The spine is approached bluntly in the known anterolateral manner between the esophagus/trachea medially and the neurovascular bundle laterally with the dilator or initially with the finger; in some cases, the superficial fascia of the neck must be opened with a sharp instrument. The operating sheath is introduced via the dilator and the endoscope is inserted into it. The further procedure is full endoscopic and uniportal, i.e., all surgical instruments are introduced under continuous visual control and irrigation through the intraendoscopic working channel (Fig. 1).

The medial anterior edges of the vertebral bodies are dissected bluntly between the longus colli muscles in the cranial direction up to the atlantoaxial region. First, the anterior caudal arch of the atlas is exposed to a width of 1.5 centimeters, preserving the insertions of the longus colli muscle. Then the odontoid process with the joint surface, the lateral edges, and the junction to the body of the axis is dissected. Next, the muscle insertions on the arch of the atlas are detached and the arch is dissected bilaterally in a lateral direction up to the atlantoaxial joints, which are opened and exposed. Then the junction is dissected from the joint processes of the axis to the body. The procedure 


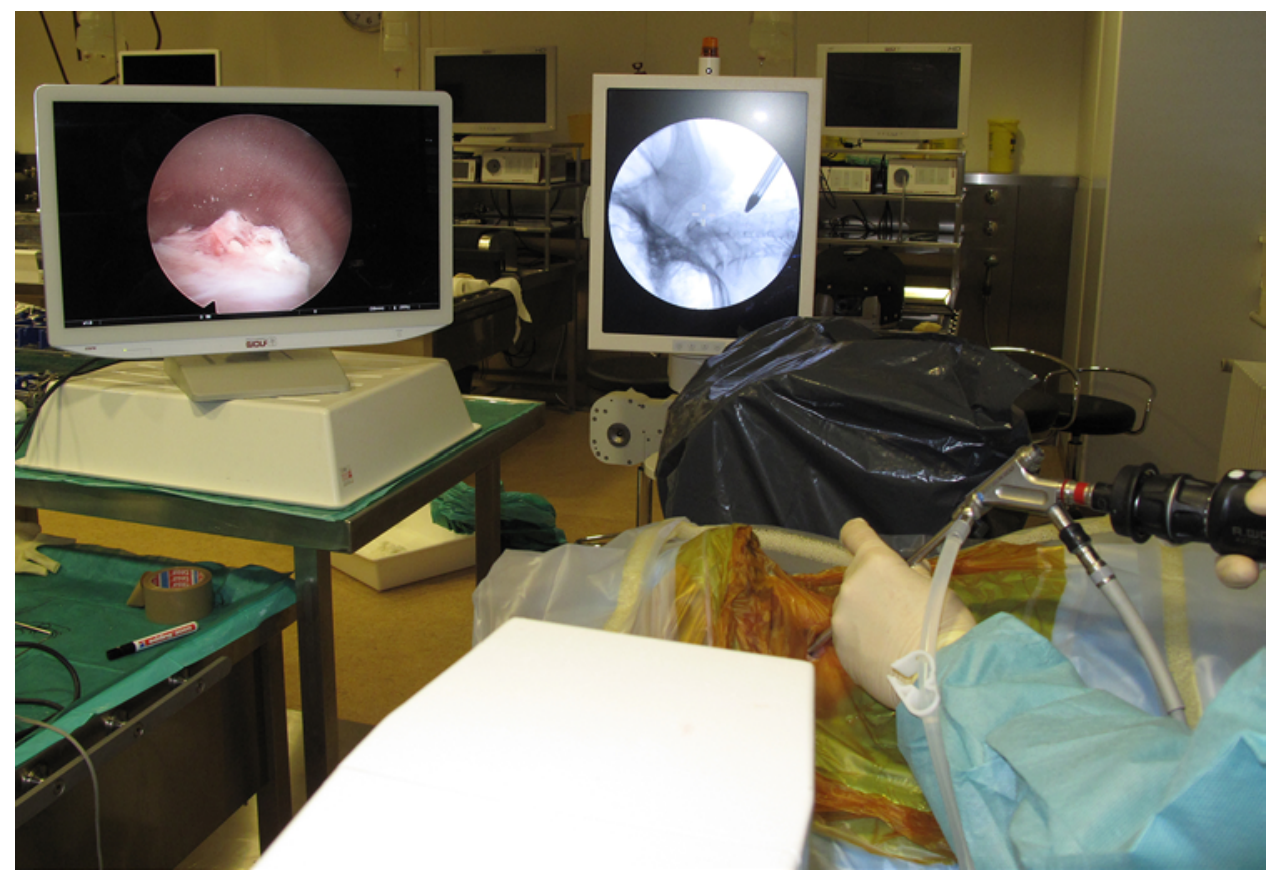

FIG. 1. Full-endoscopic uniportal technique with anterior retropharyngeal access. Figure is available in color online only.

up to this point is approximately equivalent to performing a surgical release, such as for irreducible atlantoaxial subluxation. Now the medial cranial segment of the arch of the atlas is dissected further in a cranial direction until the clivus is reached.

\section{Decompression}

For decompression of the cervicomedullary junction, i.e., the resection of the odontoid process, a horizontal groove is cut at the base of the odontoid process, preserving the posterior cortical bone. Then the rest of the odontoid process is cut in a cranial direction up to the apex. The posterior cortical bone is resected with the punch and the apex of the odontoid process with the rongeur. At the caudal posterior junction from the odontoid process to the body of the axis, bone is again resected separately. The remaining posterior membranes and ligaments (transverse ligament of the atlas, cruciate ligament of the atlas, tectorial membrane, and posterior longitudinal ligament) are resected cranially up to the foramen magnum until the dura mater of the spinal cord has been reached across the entire width and height of the excised odontoid process. The posterior edge of the clivus is exposed and the foramen magnum widened. Then, the anterior arch of the atlas is resected with a cutting tool at the width of the odontoid process, thus detaching and dissecting the atlantooccipital membrane. The clivus is exposed from the foramen magnum in an anterior direction and the foramen magnum is decompressed in an anterior direction (Figs. 2-4).

\section{Results}

All the planned steps of the operation could be performed in all 5 cadavers. Surgical access using the dilator or finger was technically easy to achieve; in two cases the fascia of the neck needed to be opened with a scissors. The retropharyngeal approach allowed the target region to be reached easily and the first clear landmark, the anterior arch of the atlas, was easily located. The anterior medial arch of the atlas was sufficient as a starting point to expose the odontoid process and then, continuing laterally along the arch, the atlantoaxial joints.

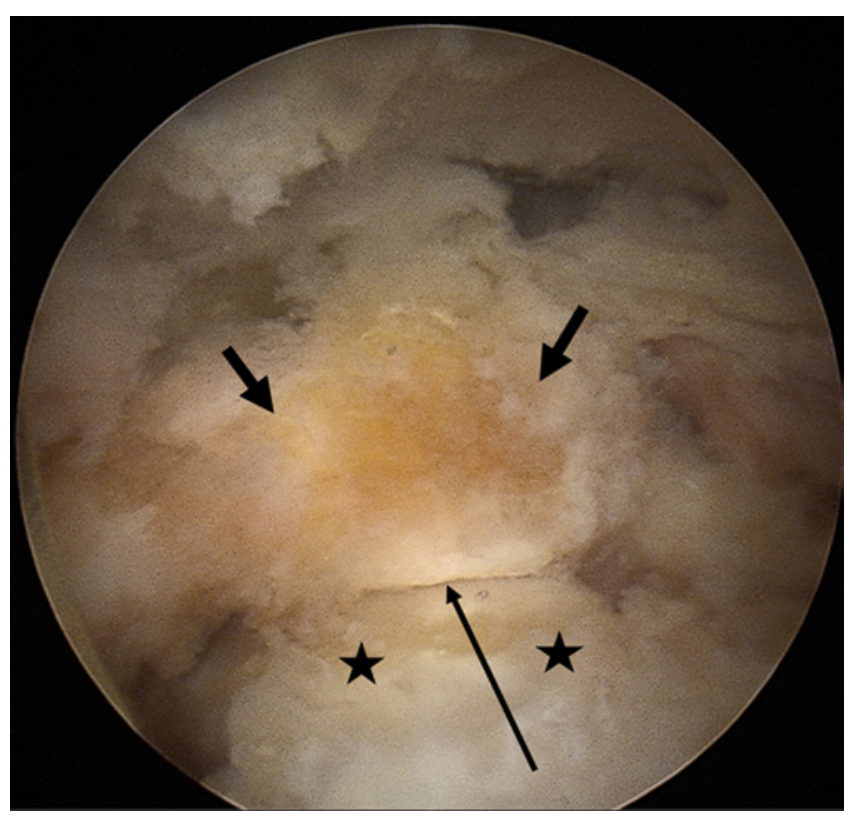

FIG. 2. Intraoperative endoscopic view of the craniocervical region with anterior arch of the atlas (short arrows), odontoid process (stars), and atlantodental joint (long arrow). Figure is available in color online only. 


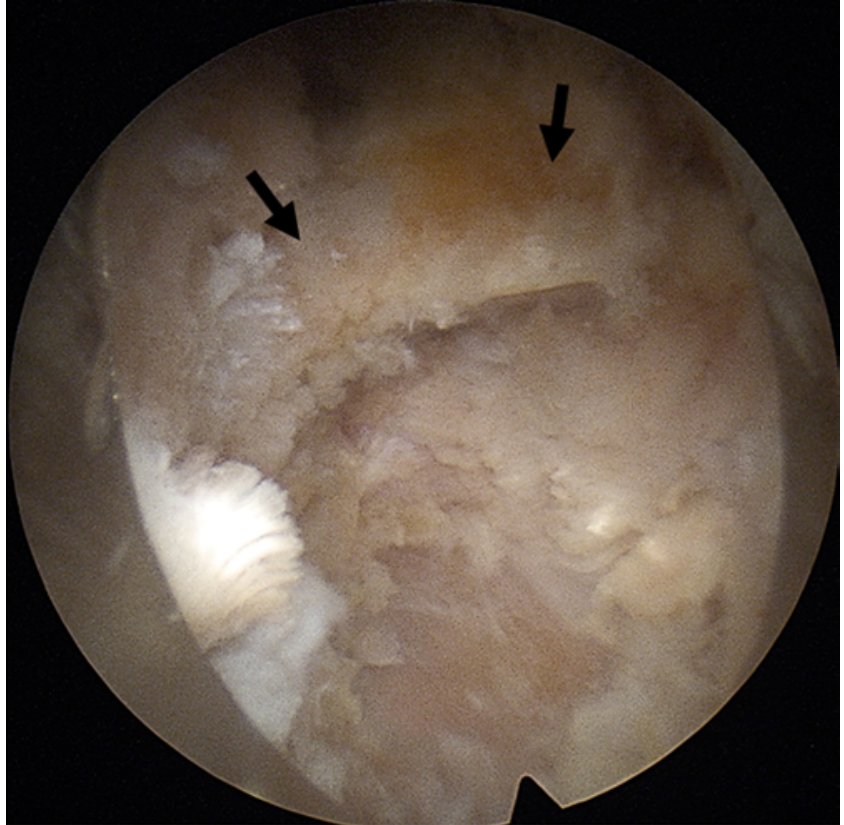

FIG. 3. View after odontoidectomy with preserved anterior arch of the atlas (arrows). Figure is available in color online only.

The odontoid process was resected with no technical difficulties in all cases. The intraoperative use of the Carm proved to be helpful in assessing the extent of decompression and maintaining the working trajectory. It proved to be helpful to preserve the posterior cortical bone and thus leave the odontoid process fixed, which simplified cutting in the cranial region. The apex of the odontoid process was held relatively firmly by the ligaments (apical ligament of dens, alar ligament) during detachment. The resection in the caudal direction at the posterior junction from the base of the odontoid process to the body of the axis was especially challenging because there was a tendency for less caudal decompression due to the usually flatter angle. The use of articulating instruments and cutting tools was technically advantageous in various maneuvers. The anterior arch of the atlas was preserved up to this step of the operation in all cases, as the flat endoscope angle also allowed the foramen magnum to be entered below the arch of the atlas. The posterior edge of the clivus could also be reached, but it was not possible to widen the foramen magnum in an anterior direction with the arch of the atlas preserved (Fig. 5).

Decompression was established based on the visible findings in combination with intraoperative radiographic imaging (complete removal of the odontoid, visualization of floating dura mater across the entire width, and from the foramen magnum to the start of the odontoid process), as is also usually performed intraoperatively for odontoidectomies in other techniques. In addition, a postoperative CT scan was obtained for the first cases (Fig. 6). The resection of the anterior arch of the atlas to approximately the width of the odontoid process was made technically difficult by the fact that after resection of all the anterior support structures, the atlas was no longer fixed, but was very mobile in the craniocaudal direction and in rotation.

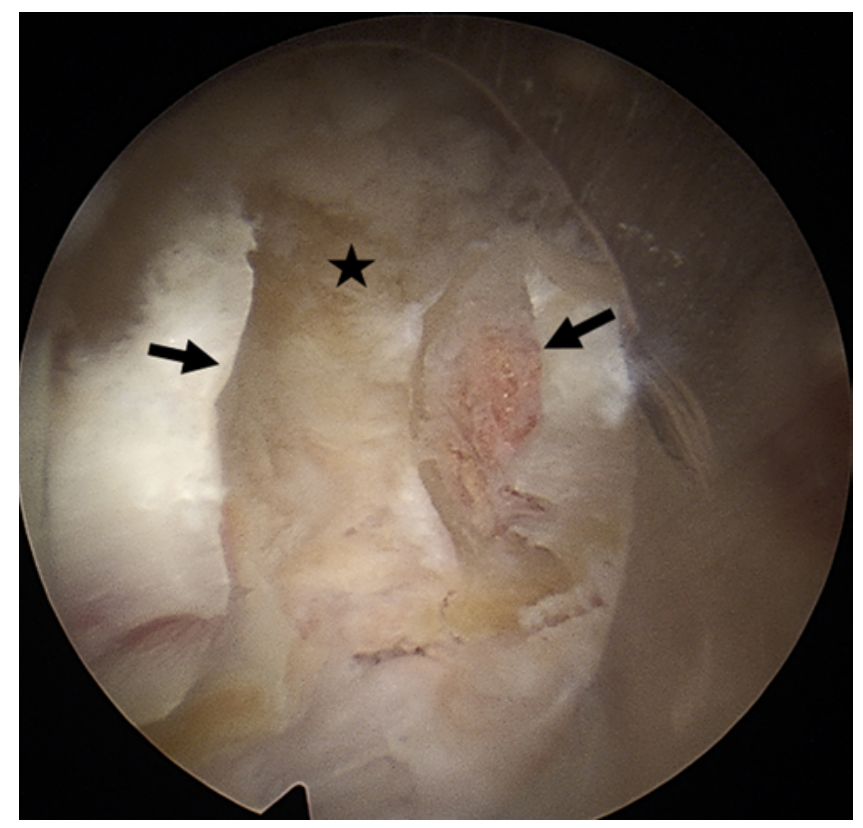

FIG. 4. Partially resected arch of the atlas (arrows) and anterior clivus (star). Figure is available in color online only.

The clivus and the foramen magnum could then be exposed and decompressed.

The option of selecting a flat to a steeper endoscope angle resulted in a large craniocaudal working area. A flatter angle is needed for most steps. A right angle between the endoscope and the cervical spine was possible in the cranial direction at most only up to the middle of the third cervical vertebral body, as cranial movement of the camera head was restricted by the lower jaw. This can make it difficult to work at the posterior edge of the axis and may require further resection of the cranial anterior vertebral body. In all cases, it was possible to achieve complete decompression without resection of the anterior arch of the atlas. If there is anterior subluxation of the atlas, the intraoperative mobility is likely even greater. For a surgical release, e.g., for irreducible horizontal or vertical subluxation, it may be necessary, depending on the intraoperative finding, to dissect the entire region laterally up to the atlantoaxial joints. For only decompression with resection of the odontoid process and the relevant soft-tissue structures, it appears to be sufficient to expose the caudal arch of the atlas at a width of approximately 1.5 centimeters, the odontoid process, and the cranial part of the anterior body of the axis. If it is still necessary to remove the anterior arch of the atlas, e.g., to reach the clivus, resection is technically feasible.

\section{Discussion}

Anterior compression of the brainstem can be caused by various pathologies of the craniocervical junction..$^{2,5,33}$ In acute or progressive myelopathy, e.g., due to irreducible instability with basilar impression, retrodental soft-tissue pannus, or infection, direct anterior decompression with odontoidectomy may be required., ${ }^{3,19,33}$ The surgical approach to the anterior craniocervical junction can be chal- 

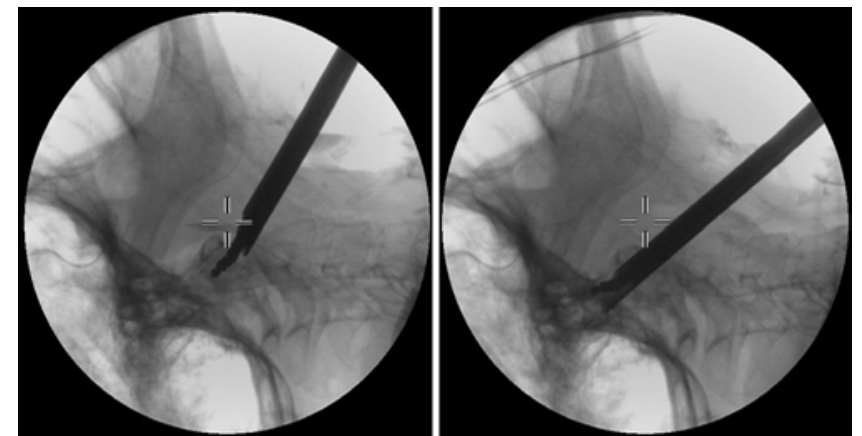

FIG. 5. Left: The oblique trajectory of the endoscope allows the arch of the atlas to be preserved. Resection of the odontoid process with an articulating cutting tool is shown. Right: Using the articulating cutting tool at the anterior edge of the clivus.

lenging due to the deep location and the surrounding neurovascular structures. Various alternative anterior, posterolateral, and lateral approaches have been described. , $^{1,5,622,36}$

The transoral approach is a direct route to the craniocervical junction. ${ }^{1,20}$ It is the most common technique used today. ${ }^{5,719}$ One technical disadvantage can be that the surgical corridor is dependent on the patient's oral cavity. $^{2,21}$ To increase mobility, splitting the palate and transmandibular or transmaxillary extension is possible. ${ }^{34}$ The endoscope-assisted technique can expand the options, especially in the cranial direction..$^{9,24}$ However, there can be approach-related problems such as velopharyngeal insufficiency, dysphonia, or dysphagia due to splitting the soft or hard palate to extend mobility, swelling of soft tissues with prolonged intubation or tracheostomy, risk of infection due to contamination of the operative area with bacterial flora of the oropharynx, or if the dura is opened, an increased risk of a CSF fistula due to insufficient soft-tissue coverage. . $^{2,5,17,32,34}$

As an alternative, the endoscopic transnasal technique was first described more than 10 years ago. ${ }^{15}$ In addition to the general advantages of endoscopy, proceeding in the cranial direction does not require splitting the palate. ${ }^{1}$ Mobility in the caudal direction is described to be problematic, and can necessitate a resection at the hard palate. In addition, there may be restrictions due to the nasal anatomy. ${ }^{1,20}$ In some cases, the nasopalatine line visible in the CT scan is considered to be the inferior limit. ${ }^{23}$ Modifications of the endoscopic transnasal technique can reduce these problems, e.g., by using a binostril approach and articulating endoscope. .11, $15,20,37^{\text {For decompression, }}$ however, it is always necessary to open the nasopharyngeal mucosa, which must be closed again after completion of the operation. ${ }^{12,37}$ No direct visual identification of the bony structures is possible when entering, making orientation more difficult, which is why some authors suggest using neuronavigation. ${ }^{11,23}$

A small number of anterior, retropharyngeal, endoscope-assisted techniques have been reported. These techniques can avoid opening the mucosa and passing through a contaminated area. The technical implementation proved to be satisfactory, with good clinical outcomes and low complication rates. ${ }^{6,36}$ The already described advantages of the retropharyngeal approach were also found in

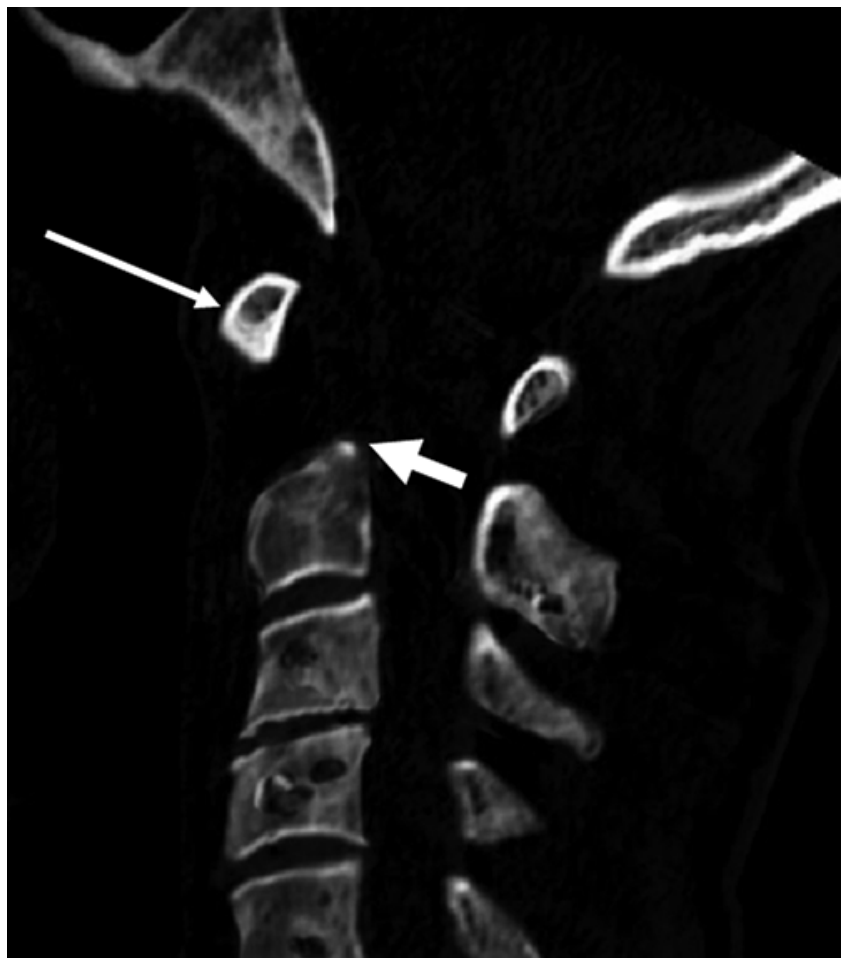

FIG. 6. CT scan after odontoidectomy showing the preserved anterior arch of the atlas (long arrow) and sufficient caudal decompression at the posterior beginning of the vertebral body (short arrow).

our study. Anterolateral, posterolateral, and transdural approaches have also been described as alternatives..$^{10,18,22,25}$

The full-endoscopic uniportal technique described here using the anterior retropharyngeal approach has the advantage already described by other authors ${ }^{6,36}$ of sterile, direct access to the craniocervical region without the necessity of involving the oropharynx or nasopharynx. The different surgical approaches have varying trajectories and thus varying working areas. In the transoral approach, the working sector therefore begins in the upper region of the axis and tends to be limited in the cranial direction; in the transnasal approach it extends cranially past the clivus and can be more problematic caudally. ${ }^{1,920,21,24,34}$ The retropharyngeal approach results in good mobility of the endoscope. Together with the $25^{\circ}$ viewing angle of the optics, this yields a large working area that appears to be less restricted than transoral or transnasal approaches. In particular, an oblique trajectory of the endoscope, the $25^{\circ}$ viewing angle, and articulating instruments make it possible to preserve the arch of the atlas (Fig. 7). Caudally, greater care must be taken when resecting the posterior edge of the axis, as there is a tendency to resect less here due to the usually flatter angle. Overall, the intraoperative use of the $\mathrm{C}$-arm is helpful for assessing the extent of the resection of the odontoid process and the further decompression. Caudal mobility may be limited when the camera head reaches the lower jaw, and mobility in the cranial direction if it is placed on the thorax. Neither situation occurred here. Nevertheless, the cervical spine may be positioned in slight overextension and nasal intubation can be used to allow the jaws to be completely closed. 


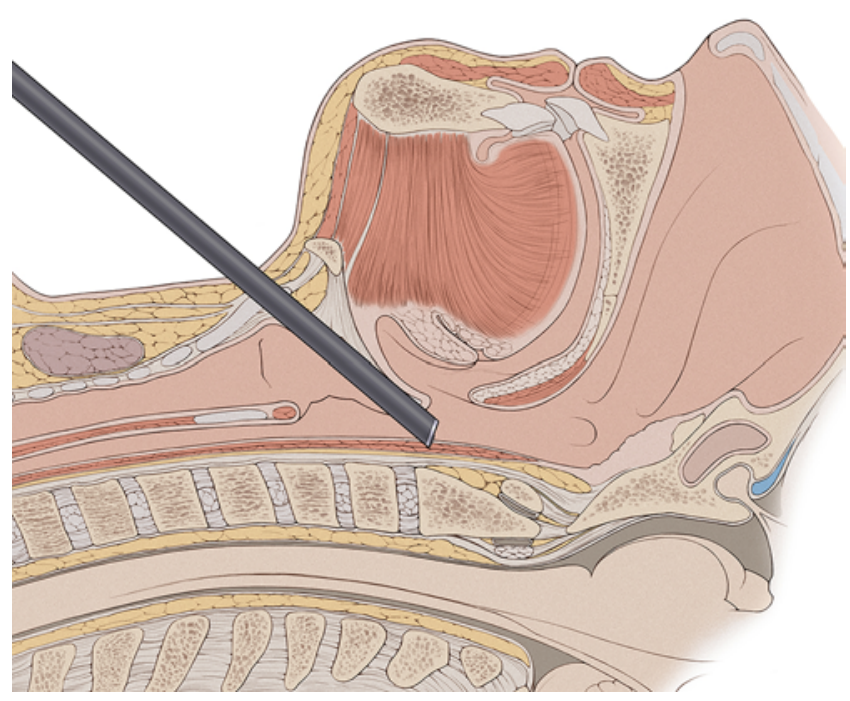

FIG. 7. Illustration showing that selecting an oblique trajectory makes a cranial working area possible with preservation of the anterior arch of the atlas. Copyright Sebastian Ruetten. Published with permission. Figure is available in color online only.

In a transoral technique, the anterior arch of the atlas is in the access route. ${ }^{20,37}$ When using an endoscopic endonasal approach, there are increasing reports of preserving the continuity of $\mathrm{C} 1 .^{12,23}$ This supports occipitocervical stability and may make it biomechanically possible to dispense with fusion, while resection tends to induce instability. ${ }^{2,12,23}$ However, it is generally not clear how and to what extent occipitocervical instability can develop and what correlations there are with resection of the anterior arch of the atlas. ${ }^{8,30}$ In all cases operated for odontoidectomy and softtissue decompression at the odontoid process in this study, it was possible to preserve the anterior arch of the atlas. To reach the clivus sufficiently, the arch of the atlas had to be resected. The very mobile atlas in the craniocaudal direction and in rotation after resection of the membrane and ligament supporting structures was remarkable.

No injuries to the dura mater were observed. Such injuries cannot be sutured and, as in other full-endoscopic spine operations ${ }^{16,26,28}$ and transoral or endoscopic transnasal operations, would have to be covered, such as with a synthetic dural substitute. . $^{3,23,37}$

The full-endoscopic uniportal technique under continuous irrigation has the proven technical advantages known from arthroscopies or other endoscopic spine operations, such as an enlarged visual field due to the $25^{\circ}$ viewing angle, excellent illumination and visualization, etc. ${ }^{16,27-29}$ It is a truly minimally invasive procedure that can reduce surgery-induced trauma. For the operator, the uniportal technique with an angled visual field can be unfamiliar at first. The same applies to the 2D work at the monitor. One general disadvantage for endoscopic procedures is the steep learning curve, ${ }^{35}$ which can be overcome with new or modified techniques, however. No other technical disadvantages were noted in the procedures conducted for this study. Nevertheless, it must be noted that cadaver studies can never reflect the entire reality of a surgical procedure, especially not the risk of injuring neural structures in operations on live patients. The results can serve as the basis for further clinical applications, in which intraoperative CT and navigation can also be taken into consideration.

\section{Conclusions}

Various techniques are available today for the direct anterior decompression of the cervicomedullary junction with odontoidectomy. In addition to the gold standardthe transoral approach-there is increasing experience with the endoscopic transnasal technique. Other alternative procedures are also being developed. The results of this anatomical study show that the craniocervical region can be satisfactorily reached, dissected, and decompressed using the full-endoscopic uniportal technique with an anterior retropharyngeal approach. All instruments used are available for clinical use and have been proven for years in other operations involving the entire spine.

Transoral, transnasal, and retropharyngeal approaches have different working regions due to their approach trajectories, which must also be taken into consideration depending on the anatomy and pathology when selecting the most suitable technique. The different surgical approaches, as already described, can thus be considered to be alternative or complementary. ${ }^{2,31}$

\section{References}

1. Alfieri A, Jho HD, Tschabitscher M: Endoscopic endonasal approach to the ventral cranio-cervical junction: anatomical study. Acta Neurochir (Wien) 144:219-225, 2002

2. Baird CJ, Conway JE, Sciubba DM, Prevedello DM, Quiñones-Hinojosa A, Kassam AB: Radiographic and anatomic basis of endoscopic anterior craniocervical decompression: a comparison of endonasal, transoral, and transcervical approaches. Neurosurgery 65 (6 Suppl):158-164, 2009

3. Burns TC, Mindea SA, Pendharkar AV, Lapustea NB, Irime I, Nayak JV: Endoscopic transnasal approach for urgent decompression of the craniocervical junction in acute skull base osteomyelitis. J Neurol Surg Rep 76:e37-e42, 2015

4. Cavallo LM, de Devitiis O, Solari D: Transnasal and transoral approaches tot he craniocervical junction: two routes for a variable destination. World Neurosurg 76:74-75, 2011

5. Crockard HA: Transoral surgery: some lessons learned. Br J Neurosurg 9:283-293, 1995

6. Dasenbrock HH, Clarke MJ, Bydon A, Sciubba DM, Witham TF, Gokaslan ZL, et al: Endoscopic image-guided transcervical odontoidectomy: outcomes of 15 patients with basilar invagination. Neurosurgery 70:351-360, 2012

7. Di Lorenzo N: Craniocervical junction malformation treated by transoral approach. A survey of 25 cases with emphasis on postoperative instability and outcome. Acta Neurochir (Wien) 118:112-116, 1992

8. Dickman CA, Locantro J, Fessler RG: The influence of transoral odontoid resection on stability of the craniovertebral junction. J Neurosurg 77:525-530, 1992

9. Frempong-Boadu AK, Faunce WA, Fessler RG: Endoscopically assisted transoral-transpharyngeal approach to the craniovertebral junction. Neurosurgery 51 (5 Suppl):S60-S66, 2002

10. Fujiwara Y, Manabe H, Sumida T, Tanaka N, Hamasaki T: Microscopic posterior transdural resection of cervical retroodontoid pseudotumors. J Spinal Disord Tech 28:363-369, 2015

11. Gempt J, Lehmberg J, Grams AE, Berends L, Meyer B, Stof- 
fel M: Endoscopic transnasal resection of the odontoid: case series and clinical course. Eur Spine J 20:661-666, 2011

12. Gladi M, Iacoangeli M, Specchia N, Re M, Dobran M, Alvaro $\mathrm{L}$, et al: Endoscopic transnasal odontoid resection to decompress the bulbo-medullary junction: a reliable anterior minimally invasive technique without posterior fusion. Eur Spine J 21 (Suppl 1):S55-S60, 2012

13. Hoffmann B: Untersuchung des Einflusses vesrchiedener Anwendungsparameter bei der Radiofrequenz-Denervierungvon Facetten- und Iliosacralgelenk zur Optimierung des Therapieerfolges [thesis]. Offenburg, Germany: Hochschule Offenburg, Fakultät Eletrotechnik \& Informationstechnik, Studiengang Medizintechnik 2017

14. Joh JY, Choi G, Kong BJ, Park HS, Lee SH, Chang SH: Comparative study of neck pain in relation to increase of cervical epidural pressure during percutaneous endoscopic lumbar discectomy. Spine (Phila Pa 1976) 34:2033-2038, 2009

15. Kassam AB, Snyderman C, Gardner P, Carrau R, Spiro R: The expanded endonasal approach: a fully endoscopic transnasal approach and resection of the odontoid process: technical case report. Neurosurgery 57 (1 Suppl):E213, 2005

16. Komp M, Hahn P, Oezdemir S, Giannakopoulos A, Heikenfeld R, Kasch R, et al: Bilateral spinal decompression of lumbar central stenosis with the full-endoscopic interlaminar versus microsurgical laminotomy technique: a prospective, randomized, controlled study. Pain Physician 18:61-70, 2015

17. Laheri V, Chaudhary K, Rathod A, Bapat M: Anterior transoral atlantoaxial release and posterior instrumented fusion for irreducible congenital basilar invagination. Eur Spine J 24:2977-2985, 2015

18. Limin L, Chunguang Z, Yueming S, Siqing H, Hao L, Quan $\mathrm{G}$, et al: A posterolateral approach to occipitoatlantoaxial ventral lesions: a report of the long-term follow-up of 23 cases. J Spinal Disord Tech 26:281-290, 2013

19. Menezes AH, VanGilder JC: Transoral-transpharyngeal approach to the anterior craniocervical junction. Ten-year experience with 72 patients. J Neurosurg 69:895-903, 1988

20. Messina A, Bruno MC, Decq P, Coste A, Cavallo LM, de Divittis E, et al: Pure endoscopic endonasal odontoidectomy: anatomical study. Neurosurg Rev 30:189-194, 2007

21. Mummaneni PV, Haid RW: Transoral odontoidectomy. Neurosurgery 56:1045-1050, 2005

22. Ohnishi Y, Iwatsuki K, Taketsuna S, Ninomiya K, Yoshimine T: Retro-odontoid synovial cyst resected via an anterolateral approach without fusion. Eur Spine J 24 (Suppl 4):S508S513, 2015

23. Ponce-Gómez JA, Ortega-Porcayo LA, Soriano-Barón HE, Sotomayor-González A, Arriada-Mendicoa N, GómezAmador JL, et al: Evolution from microscopic transoral to endoscopic endonasal odontoidectomy. Neurosurg Focus 37(4):E15, 2014

24. Qiuhang Z, Feng K, Bo Y, Hongchuan G, Mingchu L, Ge $\mathrm{C}$, et al: Transoral endoscopic odontoidectomy to decompress the cervicomedullary junction. Spine (Phila Pa 1976) 38:E901-E906, 2013

25. Riley K, Singh H, Meyer SA, Jenkins AL III: Minimally invasive surgical approach for odontoid lesions: a technical description in a case of high cervical osteomyelitis and abscess. World Neurosurg 91:332-339, 2016

26. Ruetten S, Komp M, Merk H, Godolias G: Full-endoscopic anterior decompression versus conventional anterior decompression and fusion in cervical disc herniations. Int Orthop 33:1677-1682, 2009

27. Ruetten S, Komp M, Merk H, Godolias G: Full-endoscopic cervical posterior foraminotomy for the operation of lateral disc herniations using 5.9-mm endoscopes: a prospective, randomized, controlled study. Spine (Phila Pa 1976) 33:940-948, 2008
28. Ruetten S, Komp M, Merk H, Godolias G: Full-endoscopic interlaminar and transforaminal lumbar discectomy versus conventional microsurgical technique: a prospective, randomized, controlled study. Spine (Phila Pa 1976) 33:931939,2008

29. Ruetten S, Komp M, Merk H, Godolias G: Surgical treatment for lumbar lateral recess stenosis with the full-endoscopic interlaminar approach versus conventional microsurgical technique: a prospective, randomized, controlled study. J Neurosurg Spine 10:476-485, 2009

30. Scholtes F, Signorelli F, McLaughlin N, Lavigne F, Bojanowski MW: Endoscopic endonasal resection of the odontoid process as a standalone decompressive procedure for basilar invagination in Chiari type I malformation. Minim Invasive Neurosurg 54:179-182, 2011

31. Seker A, Inoue K, Osawa S, Akakin A, Kilic T, Rhoton AL $\mathrm{Jr}$ : Comparison of endoscopic transnasal and transoral approaches to the craniovertebral junction. World Neurosurg 74:583-602, 2010

32. Shousha M, Mosafer A, Boehm H: Infection rate after transoral approach for the upper cervical spine. Spine (Phila Pa 1976) 39:1578-1583, 2014

33. Suchomel P, Buchvald P, Barsa P, Lukas R, Soukup T: Pyogenic osteomyelitis of the odontoid process: single stage decompression and fusion. Spine (Phila Pa 1976) 28:E239_ E244, 2003

34. Vishteh AG, Beals SP, Joganic EF, Reiff JL, Dickman CA, Sonntag VK, et al: Bilateral sagittal split mandibular osteotomies as an adjunct to the transoral approach to the anterior craniovertebral junction. Technical note. J Neurosurg 90 (2 Suppl):267-270, 1999

35. Visocchi M, Di Martino A, Maugeri R, González Valcárcel I, Grasso V, Paludetti G: Videoassisted anterior surgical approaches to the craniocervical junction: rationale and clinical results. Eur Spine J 24:2713-2723, 2015

36. Wolinsky JP, Sciubba DM, Suk I, Gokaslan ZL: Endoscopic image-guided odontoidectomy for decompression of basilar invagination via a standard anterior cervical approach. Technical note. J Neurosurg Spine 6:184-191, 2007

37. Yu Y, Wang X, Zhang X, Hu F, Gu Y, Xie T, et al: Endoscopic transnasal odontoidectomy to treat basilar invagination with congenital osseous malformations. Eur Spine J 22:1127-1136, 2013

\section{Disclosures}

The authors report no conflict of interest concerning the materials or methods used in this study or the findings specified in this paper.

\section{Author Contributions}

Conception and design: Ruetten, Hahn, Komp. Acquisition of data: Oezdemir, Godolias. Analysis and interpretation of data: Ruetten, Hahn, Baraliakos, Merk. Drafting the article: Hahn, Oezdemir, Baraliakos. Critically revising the article: Ruetten, Oezdemir, Baraliakos, Godolias, Komp. Administrative/technical/ material support: Hahn, Merk. Study supervision: Ruetten, Merk, Godolias, Komp.

\section{Correspondence}

Sebastian Ruetten: Center for Spine Surgery and Pain Therapy, Center for Orthopedics and Traumatology of the St. Elisabeth Group, Catholic Hospital Rhein-Ruhr, St. Anna Hospital Herne, Herne, Germany. info@s-ruetten.com. 